\title{
Revolución de la ternura: un nuevo paradigma eclesial en el pontificado de Francisco"
}

\author{
Amparo Alvarado Palacios ${ }^{* *}$
}

Recepción: 2 de julio de 2018 • Aprobación: 28 de julio de 2018

\section{Resumen}

Se quiere ofrecer una lectura del pensamiento del papa Francisco, intuyendo en ello un planteamiento de un nuevo paradigma eclesial, una nueva visión de ser humano y de mundo, y una nueva eclesiología y espiritualidad, manifiesta en la categoría ternura. Sobre las bases del Concilio y escuchando no solo a las Iglesias locales de todo el mundo sino a otras Iglesias, el papa está invitando a una revolución. Pasar de formulaciones teóricas y frías a compromisos y gestos concretos de acogida, de cariño verdadero, de humilde servicio y, sobre todo, de cercanía e identificación con los pobres, con lo que incita a dar testimonio de nuestra identidad humana, eclesial y espiritual con expresiones concretas de ternura hasta vivir la mística de la ternura.

Palabras clave: Francisco, ternura, novedad, diálogo, misericordia.

* Artículo de reflexión presentado en el IV Encuentro de la Red de Teólogos y Teólogas del Cebitepal-Celam, Bogotá, 27-29 de julio de 2016. Citar como: Alvarado Palacios, A. (2019). Revolución de la ternura: nuevo paradigma eclesial en el pontificado de Francisco. Albertus Magnus, X(2), 165-184. DoI: https://doi.org/10.153322/5005413.5218.

* Instituto Sur Andino de Investigación y Acción Solidaria, Perú. Correo electrónico: florderetama77@gmail.com 


\title{
Revolution of tenderness: A new ecclesial paradigm in the pontificate of Francisco
}

\begin{abstract}
It is desirable to offer a Lecture of the Pope's thought, suspecting in it an approach of a new ecclesial paradigm. A new vision of being human and from the world; a new ecclesiology and spirituality; whose pillar is "tenderness". On the basis of the Council and listening not only to the local Churches around the world, but to other Churches, the Pope is inviting to a revolution. Switching from theoretical and cold formulations to concrete commitments and gestures of welcome, of true affection, of humble service and, above all, of closeness and identification with the poor. With this, it encourages us to bear witness to our human, ecclesial and spiritual identity with concrete expressions of tenderness, until living a mystique of tenderness.
\end{abstract}

Keywords: Francisco, tenderness, novelty, dialogue, mercy, mystique.

\section{Revolução da ternura: um novo paradigma eclesial no pontificado de Francisco}

\section{Resumo}

Queremos oferecer uma leitura do pensamento do papa, intuindo nela uma abordagem para um novo paradigma eclesial. Uma nova visão de ser humano e do mundo; uma nova eclesiologia e espiritualidade; que têm o eixe na "ternura". Com base no Concilio Vaticano II e não apenas escutando as Igrejas locais em todo o mundo, mas também umas outras Igrejas, o papa está convidando uma revolução. Passando de formulações teóricas e frias para compromissos concretos e gestos de acolhida, de verdadeiro afeto, de serviço humilde e, sobretudo, de proximidade e identificação com os pobres. Com isso, incentiva-nos a testemunhar a nossa identidade humana, eclesial e espiritual com expressões concretas de ternura, até viver uma mística da ternura.

Palavras-chave: Francisco, ternura, dialogo, novidade, misericórdia, mística. 


\section{Introducción}

Se podría señalar que Francisco ha irrumpido en nuestro tiempo con una mochila de nuevos paradigmas. La novedad no estriba tanto en los contenidos que transmite sino en el modo de hacerlo. Como es de notar, su pontificado tiene en su esencia el pensamiento del Concilio Vaticano II dicho y vivido de una manera de por sí revolucionaria. De todo ese bagaje de cambios que este papa está haciendo en la Iglesia, se va a tratar de un detalle de gran trascendencia y de múltiples alcances: su constante insistencia en la ternura.

Indica Francisco (2014): “El Hijo de Dios, en su encarnación, nos invitó a la revolución de la ternura" (n. 88). Está hablando de una empresa desafiante que brota del misterio de la Encarnación del Verbo. En esta comunicación, se quiere desvelar el contenido profundo de esta expresión que, sin duda, su Santidad está intentando mostrar a la Iglesia y al mundo. Se quiere presentar este nuevo paradigma de reflexión y práctica eclesial desde tres dimensiones: una nueva visión de humanidad y de mundo, una nueva visión-misión de Iglesia y una visión y práctica de una nueva espiritualidad creyente.

Se abordará esta triple dimensión del pensamiento papal haciendo una lectura transversal de los gestos (cfr. Torralba, 2014) y palabras del papa que tienen en la ternura una sustancial argumentación y exhortación cristiana constantes. Entendiendo esta palabra en el sentido que le da Rocchetta (2001), "la ternura es la fuerza más humilde; pero es la que tiene mayor poder para cambiar el mundo" (p. 13). Por tanto, la ternura abarca una dimensión interior y exterior, actitud y acción, argumento y práctica, motivo por el que se termina con una reflexión sobre la mística de la ternura.

\section{Nueva visión de humanidad y de mundo: cultura del diálogo y la ternura}

Para entender la antropología y la cosmovisión de Francisco (2014), se debe considerar cómo encuentra el papa a esta humanidad y a este mundo. De una o de otra forma descubre en general una cultura de antiternura, manifestada en diferentes formas: miedo, desesperación, falta de respeto, violencia, inequidad, vida con poca dignidad (nn. 52, 60). La consideración de excluidos como desechos (n. 53), producto, sin duda, de un sistema económico injusto (n. 59), donde prima el consumismo y la inequidad que daña el tejido social, donde los pobres sobreviven en 
grandes dolores (nn. 60, 63; Francisco, 2015, n. 51). Sistema lleno de individualismos que debilitan los vínculos entre personas (n. 67), cambios que deterioran el mundo y la calidad de vida de la humanidad (Francisco, 2015, n. 18).

Francisco (2015) denuncia una cultura del descarte ligada a problemas sociales y ecológicos (nn. 22, 43; Francisco, 2014, n. 53) y evidencia síntomas de degradación social, ruptura de lazos de integración y comunión social (n. 46), así como nuevas guerras disfrazadas de nobles reivindicaciones (n. 57), para justificar que lo que sucede es que se ha dejado de pensar en los fines de la acción humana (n. 61). Se tolera que unos se consideren más dignos, más humanos, con más derechos que otros (n. 90), no se ve que la libertad humana está enferma por necesidades inmediatas, el egoísmo y la violencia (n. 105), relativismos que finalmente empujan a maltratar a las personas (n. 123).

Con lo anterior Francisco (2014) hace tomar conciencia de que la anticultura de la violencia, de la inequidad, del individualismo y del relativismo está haciendo del mundo una realidad que destruye al ser humano y niega su primacía (n. 55) y su entorno. Situación dramática que invita a cambiar con la ternura.

Francisco (2015) pide revisar la antropología cristiana actual, quiere una "adecuada antropología" (n. 118) que teniendo al ser humano en alto valor esté atenta a antropocentrismos desviados (n. 119). Propone, por tanto, unir la antropología a la ética porque la "degradación ambiental y la degradación humana y ética están íntimamente unidas" (n. 56). En Evangelii gaudium (Francisco, 2014), pide unir la antropología no solo a la ética sino a lo social para "crear un equilibrio y un orden social más humano" (n. 57). Por eso, llama al ser humano "administrador responsable" (nn. 116, 118) y así recupera lo propio del ser humano, puesto que un antropocentrismo desviado lleva a un estilo de vida también desviado.

Para superar el antropocentrismo desviado, Francisco (2015) incluye, pues, su visión del mundo. Esta la manifiesta claramente en la encíclica Laudato si', donde nos habla de una "ecología integral", puesto que él entiende la relación con la naturaleza en el mismo nivel de relación entre los humanos (n. 137), y así une el problema ambiental al económico y al social: "nos impide entender la naturaleza como algo separado de nosotros o como un mero marco de nuestra vida" [...] "estamos incluidos en ella, somos parte de ella y estamos interpenetrados" [...] "no hay dos crisis separadas, una ambiental y otra social, sino una sola y compleja crisis socio-ambiental" (n. 139). Una visión que permite aceptar que "las distintas criaturas se relacionan conformando esas unidades mayores que hoy llamamos 'ecosistemas'. [...] Aunque no tengamos conciencia de ello, dependemos de ese conjunto para nuestra propia existencia" (n. 140). 
Por tanto, Francisco (2015) propone denunciar "el crecimiento económico que tiende a producir automatismos y a homogeneizar, en aras de simplificar procedimientos y a reducir costos" y proponer "considerar una realidad más amplia [...] una mirada más integral e integradora" (n. 141). También Francisco advierte, refiriéndose a las instituciones sociales, que "todo lo que las dañe entraña efectos nocivos, como la pérdida de la libertad, la injusticia y la violencia", y así afecta nuestra "ecología social". Se refiere del mismo modo a salvaguardar una "ecología cultural": "Junto con el patrimonio natural, hay un patrimonio histórico, artístico y cultural, igualmente amenazado. Es parte de la identidad común de un lugar y una base para construir una ciudad habitable" (n. 143).

Francisco nos invita, pues, a reconocer la dignidad de la naturaleza en su amplia dimensión, la dignidad humana y sus derechos naturales, sociales, económicos, culturales y políticos como una forma de convivencia digna. No sacralizando las realidades temporales, sino respetando su autonomía. Con ello la Iglesia se pronuncia, con validez eterna, allí donde termina la sabiduría de este mundo. El mensaje es de optimismo en el mismo sentido de Gaudium et spes. En suma, lo ético hay que verlo en lo social, en lo económico y en lo cultural. Esa es su visión del ser humano y del mundo, atravesado por su insistencia en el diálogo y la ternura.

En Evangelii gaudium, Francisco (2014) usa 56 veces la palabra diálogo, mientras que en Laudato si' (2015) la emplea 27 veces y la define con claridad:

Un diálogo es mucho más que la comunicación de una verdad. Se realiza por el gusto de hablar y por el bien concreto que se comunica entre los que se aman por medio de las palabras. Es un bien que no consiste en cosas, sino en las personas mismas que mutuamente se dan en el diálogo. (n. 142)

Definición que enuncia su pensamiento respecto del ser humano y de todo lo que conlleva el diálogo. La antropología de Francisco es relacional, concibe una humanidad hecha para el encuentro con todos los seres creados y con su Creador. En el diálogo entre Dios y el ser humano, según Francisco, hay que dejar claro el lugar de cada sujeto interlocutor. Habla el papa de primerear: "La comunidad evangelizadora experimenta que el Señor tomó la iniciativa, la ha primereado en el amor (cf. 1 Jn 4, 10)" (n. 24), con lo que está sentando la base fundamental de la fe sobre quien es posible dialogar: Dios es el primero, no solo como convicción sino como experiencia, así como reconocer que esta experiencia y conocimiento es un acto provocado por Dios en su voluntad salvífica. Por tanto, 
conocer y experimentar pasa a ser una sola realidad de gracia, más de las veces posteriormente explicitada en lenguaje teológico.

Deja claro que en este espacio de interlocución hay que distinguir la naturaleza de cada interlocutor. Es propio de Dios la iniciación del diálogo, pronunciando su palabra: "Escucha, Israel: Yahvé, nuestro Dios, es Yahvé-único" (Dt 6, 4), y del ser humano es propio escuchar y responder a esa Palabra según el pensamiento de Dios. En el encuentro entre Dios y el ser humano, aquel es preeminente y este, desde abajo, lo escucha y lo acoge. El ser humano sigue siendo tal también cuando es Dios quien le habla. La capacitas humana en orden a la gracia y a la Palabra de Dios es siempre una capacitas finita.

Francisco es fiel al Dios bíblico, que es comunicación originaria, es el que tiene la iniciativa de dialogar con el ser humano; este es por gracia receptividad histórica (Pikaza, 2006, p. 15). “La persona humana es siempre y desde el principio relación total a Dios" (Andrade, 1999, p. 103). Una relación ascendente por esencia: el ser humano busca a Dios como al que es siempre antes y más que él, ante quien le queda escuchar, acoger y responder en obediencia.

"Comunicarse entre los que se aman" supone, pues, reconocer su dimensión interpersonal (yo-tú/nosotros), su dimensión interpelante que compromete con el otro (dimensión ética del diálogo) y su dimensión creadora (todo diálogo construye algo nuevo). Es desde esta dimensión teológica del diálogo que se puede descubrir la profundidad de la ternura, puesto que la ternura muestra la irreductibilidad del otro. "Una persona se me revela y me interpela para un diálogo de igual a igual; [...] El asombro que siento por mí mismo me remite al asombro que debería sentir por todos los demás que me rodean" (Rocchetta, 2001, p. 70), así como muestra la razón de ser del diálogo: la caridad. La caridad es el fundamento de la ternura, y esta impide a la caridad reducirse a una moral del deber o de mínimo necesario, y le ofrece, por así decirlo, el corazón, un corazón palpitante, acogedor, que sabe dar y compartir, capaz de compasión, de benevolencia afable y de amistad gratuita (p. 17).

En resumen, el papa tiene una visión del ser humano y del mundo comunional. Una comunión que no se construye con palabras sino con gestos de cariño, de generosidad, de humilde disponibilidad para el otro y, en especial, para los pobres. Puesto que "la ternura [...], pertenece a nuestro mismo ser: su ausencia es signo de una naturaleza incompleta" (Canciani, 2001, citado por Rocchetta, 2001, p. 15). 


\section{Nueva visión de Iglesia: sacramento de la lectura}

¿Qué hay detrás de estas palabras de Francisco (2014) que han dado mucho de qué hablar?

Prefiero una Iglesia accidentada, herida y manchada por salir a la calle, antes que una Iglesia enferma por el encierro y la comodidad de aferrarse a las propias seguridades. No quiero una Iglesia preocupada por ser el centro y que termine clausurada en una maraña de obsesiones y procedimientos. (n. 49)

Si antes hablaba de un antropocentrismo desviado, ahora hablará de una eclesiocentrismo enfermo: Iglesia encerrada en sí misma que crea desigualdades y distancias entre fieles y pastores, doctrinaria y rígida. Francisco (2014) denuncia:

Es necesario que reconozcamos que, si parte de nuestro pueblo bautizado no experimenta su pertenencia a la Iglesia, se debe también a la existencia de unas estructuras y a un clima poco acogedores [...] una actitud burocrática para dar respuesta a los problemas, simples o complejos, de la vida de nuestros pueblos. (n. 63)

La falta de espacios de diálogo familiar, [...] la falta de acompañamiento pastoral a los más pobres, la ausencia de una acogida cordial en nuestras instituciones, y nuestra dificultad para recrear la adhesión mística de la fe en un escenario religioso plural. (n. 70)

Francisco insiste en las bases eclesiológicas del Concilio: Iglesia Pueblo de Dios, Iglesia comunión e Iglesia en diálogo con el mundo. La constitución dogmática Lumen gentium (Pablo, 1964) la presenta "como un sacramento, o sea, signo e instrumento de la unión íntima con Dios y de la unidad de todo el género humano" (n. 1). El misterio de comunión de la Iglesia tiene su fuente en Dios mismo, que se revela como una comunión interpersonal de amor y llama a la salvación a todos los hombres, ampliamente expuesta antes. Salvación de la humanidad deseada desde el seno de la Trinidad. En el lenguaje papal, quiere una Iglesia "sacramento de la ternura".

Francisco (2014) ha vivido primero su ser parte de la Iglesia pueblo, en gestos de sencillez, como estar confundido en medio de la gente, su preferencia de visitar las cárceles, no aceptar vestimentas que denoten privilegios, etc. De ahí que planteara también, en consonancia con el Dios que primerea, que la Iglesia debe hacerlo: "La Iglesia en salida es la comunidad de discípulos misioneros que primerean, que se involucran, que acompañan, que fructifican y festejan" (n. 24). 
Concibe a la Iglesia como Pueblo de Dios, afirmada como sujeto social e histórico insertado en el peregrinar del conjunto de los pueblos. Por ello, no puede considerar ajena ninguna preocupación o dimensión de la existencia colectiva de los pueblos, como lo subraya Gaudium et spes. En medio de ellos, en cuanto testigo de una reconciliación que supera las divisiones, ha de prestar su servicio y testimonio sacerdotal y profético. Francisco señala:

La comunidad evangelizadora se mete con obras y gestos en la vida cotidiana de los demás, achica distancias, se abaja hasta la humillación si es necesario, y asume la vida humana, tocando la carne sufriente de Cristo en el pueblo. Los evangelizadores tienen así "olor a oveja" y estas escuchan su voz. (n. 24)

Francisco, en concordancia con el Concilio, describe, pues, una eclesiología circular que se extiende e incluye sin excepción de nadie, y no escatima esfuerzos variados y en todos los campos de la vida humana para alcanzar su fin: la comunión. Recuerda que esta comunión no es un aspecto de la Iglesia, sino que es una dimensión constitutiva de ella: "La comunión encarna y manifiesta la esencia misma del misterio de la Iglesia" (Pablo 1964, n. 11); es el núcleo profundo del misterio de la Iglesia. Esta participación crea la koinonía en la Iglesia y la impulsa a dilatarla a toda la humanidad. Como Juan Pablo II (1989) afirmaría:

La comunión de los cristianos con Jesús tiene como modelo, fuente y meta la misma comunión del Hijo con el Padre en el don del Espíritu Santo: los cristianos se unen al Padre al unirse al Hijo en el vínculo amoroso del Espíritu [...] La comunión de los cristianos entre sí nace de su comunión con Cristo [...] esta comunión fraterna es el reflejo maravilloso y la misteriosa participación en la vida íntima de amor del Padre, del Hijo y del Espíritu Santo. (n. 18)

De lo contrario, desdice su ser. No es posible hablar de una comunión sin el Espíritu Santo:

El mismo Espíritu Santo es la armonía, así como es el vínculo de amor entre el Padre y el Hijo. Él es quien suscita una múltiple y diversa riqueza de dones y al mismo tiempo construye una unidad que nunca es uniformidad sino multiforme armonía que atrae. (n. 117)

Francisco (2014) pedirá una Iglesia cuya comunión atraiga “a los cristianos de todas las comunidades del mundo, quiero pediros especialmente un testimonio de comunión fraterna que se vuelva atractivo y resplandeciente" (n. 99). 
Propone una comprensión de la Iglesia como "comunión misionera", con lo que recoge de Lumen gentium (1964) y de Aparecida, reforzando el hecho de que la comunión se verifica en la misión, en la evangelización. Al respecto, afirma: “En un dinamismo evangelizador que actúa por atracción [...] Solo Él puede suscitar la diversidad, la pluralidad, la multiplicidad y, al mismo tiempo, realizar la unidad" (n. 131).

El nuevo paradigma de Francisco estriba en que todas estas verdades ya sabidas y difundidas sobre el ser de la Iglesia se resume en que ella está llamada a ser sacramento de la ternura de Dios. Rocchetta (2001), aunque escribe antes del pontificado de Francisco, expresa muy bien lo que la persona y el pensamiento papal transmiten:

Se quiere que la Iglesia se presente ante el mundo como el sacramento de la ternura de Dios, de un Dios de bondad y de gracia, y no de castigo y de miedo. La verificación teológica sobre la ternura lleva consigo notables implicaciones de orden eclesiológico. [...] La teología de la ternura supone, de hecho, la praxis de la ternura; pone en crisis todo un modo de ser cristianos que se queda en la superficie o se contenta con un cristianismo mediocre, [...]. Fuera del evangelio de la ternura, es fuerte la tentación de ser o de volver a ser una Iglesia del dominio y de la exclusividad. [...] sin ese secreto de armonía interior, de gozo de creer, de esperar y de amar, la comunidad de los cristianos corre el riesgo de transformarse en una Iglesia enrocada en sí misma, rígida, ligada solo a las instituciones y privada de espíritu de profecía, incapaz de anunciar de forma creíble la novedad salvífica de la pascua. (pp. 20-21)

Francisco actualiza "la Iglesia que quiso el Concilio que no es la Iglesia encerrada en sí misma, en sus problemas, en su organización, en sus intereses y en sus normas, sino la Iglesia que dialoga con el mundo, con la sociedad y con la cultura de nuestro tiempo" (Castillo, 2002, p. 26). Ser "Iglesia en salida" (Francisco, 2014, nn. 17, 20-24, 26) es, pues, dar testimonio de ser "sacramento de la ternura": que los creyentes sin distingos de nada den un paso para salir a la calle, al mundo, para transformar rescatando a la humanidad y al cosmos, con gestos de compasión y ternura. Haciendo de la solidaridad señal de fraternidad verdadera. Que en las comunidades cristianas se den experiencias de sencillez, acogida, ternura, en vez de adoctrinamientos fríos y sin calidez humana. Que la tarea evangelizadora sea realizada con testimonios de amor incondicional traducido en métodos que combinen lo profundo con lo sencillo y lo afectuoso. Que sea una Iglesia que no se limite a hablar de los pobres, sino ser pobre y para los 
pobres, y deje de lado cualquier honor y privilegios que distancian a la fraternidad y sororidad, ya que "la evangelización se hace de rodillas", puesto que "lo esencial, según el evangelio, es la misericordia" (Francisco, 2014a).

La Iglesia necesita la mirada cercana para contemplar, conmoverse y detenerse ante el otro cuantas veces sea necesario. [...]. La Iglesia tendrá que iniciar a sus hermanos - sacerdotes, religiosos y laicos - en este "arte del acompañamiento", para que todos aprendan siempre a quitarse las sandalias ante la tierra sagrada del otro (cf. Ex 3, 5). Tenemos que darle a nuestro caminar el ritmo sanador de proximidad, con una mirada respetuosa y llena de compasión pero que al mismo tiempo sane, libere y aliente a madurar en la vida cristiana. (Francisco, 2014, n. 169)

Una nueva eclesiología que supere realidades eclesiales cerradas, elitistas, separadas de la vida cotidiana, para proyectar una nueva manera de evangelizar, cambiar los métodos pastorales. Francisco quiere que la ternura sea ese nuevo método. No resulta difícil interpretar cuáles podrían ser las estrategias de ese método. Sin duda, serían la escucha, el diálogo y el compromiso amoroso, que darán como resultado "algo nuevo", que el Reino de Dios se propagará activamente por los confines de la tierra a través de una reparadora conversión.

\section{Nueva espiritualidad: "Testigos de la misericordia y de la ternura del Señor"}

Francisco (2014) ve con dolor no solo un antropocentrismo desviado y un eclesiocentrismo enfermo, sino que también constata una vida cristiana mediocre y débil. Por eso, de una visión de ser humano relacional y comunional, y de una visión de una Iglesia misionera y dialogante, ya se puede concluir la espiritualidad que sustenta Francisco. Lejos de ser inhumana, intimista e individual (n. 183), nos presenta una espiritualidad encarnada y relacional. Al hacer un llamado en Evangelii gaudium a buscar lo esencial del cristianismo: Jesucristo está recordando las consecuencias de la Encarnación en la vida cristiana, en la vida y en la misión de los creyentes:

Confesar que el Hijo de Dios asumió nuestra carne humana significa que cada persona humana ha sido elevada al corazón mismo de Dios. Confesar que Jesús dio su sangre por nosotros nos impide conservar alguna duda acerca del amor sin límites que ennoblece a todo ser humano. (n. 178) 
Para ser evangelizadores de alma también hace falta desarrollar el gusto espiritual de estar cerca de la vida de la gente, hasta el punto de descubrir que eso es fuente de un gozo superior. La misión es una pasión por Jesús, pero, al mismo tiempo, una pasión por su pueblo. (n. 268)

Francisco (2014) habla así de un cristianismo verdadero, del que no tiene más meta que la total identificación con Cristo, como invita Aparecida: “Llegar a la estatura de la vida nueva en Cristo, identificándose profundamente con Él y su misión" (n. 281). Ante "el desafío de revitalizar nuestro modo de ser católico y nuestras opciones personales por el Señor, para que la fe cristiana arraigue más profundamente en el corazón de las personas y los pueblos latinoamericanos" (n. 13), resta la firme convicción de cambiar el modo de dar testimonio cristiano. Francisco (2014) afirmará: “Todo cristiano es misionero en la medida en que se ha encontrado con el amor de Dios en Cristo Jesús; ya no decimos que somos 'discípulos' y 'misioneros', sino que somos siempre 'discípulos misioneros'” (n. 120).

De la centralidad de Jesucristo como "gusto espiritual", Francisco (2014) extiende las implicaciones en el modo de vivir la relación con Dios, con los semejantes y con el cosmos. Desarrolla la fraternidad ampliamente, y lo novedoso es que, siguiendo a san Francisco de Asís, le da uno tono místico:

Sentimos el desafío de descubrir y transmitir la mística de vivir juntos, de mezclarnos, de encontrarnos, de tomarnos de los brazos, de apoyarnos, de participar de esa marea algo caótica que puede convertirse en una verdadera experiencia de fraternidad, en una caravana solidaria, en una santa peregrinación. (n. 87)

De ahí se extiende que para el discípulo de Jesús no es secundaria la opción por los pobres; siendo esencia de la espiritualidad del Maestro, lo es también para ellos. Francisco (2014) manifiesta que "la opción por los pobres es una categoría teológica antes que cultural, sociológica, política o filosófica", porque "Dios les otorga su primera misericordia" (n. 198). Jesús de Nazaret, un "hombre del Espíritu", eligió nacer en la pobreza, vivir ignorado y morir injustamente condenado.

La espiritualidad cristiana para Francisco (2015) está en consonancia con Aparecida, "es una espiritualidad encarnada en la cultura de los sencillos, que, no por eso, es menos espiritual, sino que lo es de otra manera" (n. 263), ya que el estilo de vida cristiana como camino de identificación con Cristo no puede menos que considerar:

Sin la opción preferencial por los más pobres, “el anuncio del Evangelio, aun siendo la primera caridad, corre el riesgo de ser incomprendido 
o de ahogarse en el mar de palabras al que la actual sociedad de la comunicación nos somete cada día". (Francisco, 2014, n. 198)

Francisco lo afirma con la novedad de que esa opción es con corazón: se trata de una acción amante, de dejarse movilizar por el Espíritu, preocupación por su persona, ya que "el verdadero amor siempre es contemplativo, nos permite servir al otro no por necesidad o por vanidad, sino porque él es bello, más allá de su apariencia, [...]" (Francisco, 2014, n. 198). Invita a "colocar a los excluidos en el centro del propio camino" (Francisco, 2016).

A una espiritualidad que también asume el compromiso de cuidar la creación, Francisco (2015) la llama "evangelio de la creación" (nn. 62-100). Si el cuerpo es un sujeto, un tú, también lo es la naturaleza toda, que está clamando, llamando a considerarla para cambiar los estilos de vida de los cristianos, como bien invita: "Hace falta volver a sentir que nos necesitamos unos a otros, que tenemos una responsabilidad por los demás y por el mundo, que vale la pena ser buenos y honestos" (n. 229); "La conversión ecológica que se requiere para crear un dinamismo de cambio duradero es también una conversión comunitaria" (n. 219). Espiritualidad, sin duda, que lleva a devolver la dignidad del mundo, un estilo de vida, portadora de vida, estilo que da el seguimiento de Jesús, que conoció y trató su entorno como realidades vivas y para dar vida. Estilo que no parte del poder y dominio por interés instrumental, sino de gratuidad e inclusión, puesto que "el gemido de la hermana Tierra se une al gemido de los abandonados del mundo" (n. 53).

El papa insiste, pues, en la fraternidad, en la opción por los pobres, en el cuidado del cosmos, pero, su novedad está en que lejos de quedarse en prácticas sociales, de valor sí, ha de manifestarse en gestos de ternura y misericordia: "Nos conmueve la actitud de Jesús: no escuchamos palabras de desprecio, no escuchamos palabras de condena, sino solo palabras de amor, de misericordia, que invitan a la conversión" (Francisco, 2014a). Al referirse a la conversión ecológica indica: "Esta conversión supone diversas actitudes que se conjugan para movilizar un cuidado generoso y lleno de ternura" (n. 220).

Para Francisco (2014a), la misericordia tiene que ver con la calidez de la vida cristiana y con su coherente compromiso social: “Un poco de misericordia hace el mundo menos frío y más justo" (n. 220), con lo que quiere místicos, ya que solo se puede alcanzar ser tiernos y misericordiosos estando llenos de una gracia que Dios da a los humildes y que posibilita "la alegría de redescubrir y hacer fecunda la misericordia de Dios" (n. 220).

Lo que Francisco pretende es mostrar un camino de plenitud humanocristiana, que se logra al identificar también la experiencia de diálogo de ternura 
y misericordia con el Dios vivo, presente en cada ser humano, en sus diferentes interrelaciones y en el universo entero, como una experiencia mística, ya que "la experiencia mística es esencialmente vínculo, relación, contacto amoroso con una realidad inmensamente valorada y concebida como el centro secreto más íntimo de la existencia y como fuente permanente de la misma" (Domínguez, 2003, p. 6). Por eso, la consecuencia principal de la experiencia mística es abrir cauces a una evangelización que demanda una mayor práctica de la fraternidad. Cuanto mayor es la experiencia mística, mayor es la misericordia, la comunión y el compromiso personal y comunitario.

Para vivir como comunidad, hay que pasar del "querer estar juntos", que transforma la "masa" en "pueblo", al querer estar juntos en Cristo, que hace Pueblo de Dios. Querer amar como Cristo pondrá a la comunidad en la dinámica de un "mismo sentir", pues Jesús,

en su predicación mandó claramente a los hijos de Dios que se trataran como hermanos. Pidió en su oración que todos sus discípulos fuesen uno. Más todavía, se ofreció hasta la muerte por todos, como Redentor de todos. Nadie tiene mayor amor que este de dar uno la vida por sus amigos (Io 15, 13). Y ordenó a los Apóstoles predicar a todas las gentes la nueva angélica, para que la humanidad se hiciera familia de Dios, en la que la plenitud de la ley sea el amor. (Pablo, 1965, n. 32)

Ser agentes de comunión y participación exige cambiar la lógica del sistema actual de organización económica, política y social, de consumo, e individualista, en beneficio de la lógica cristiana del servicio humilde hasta el martirio. El sistema anticomunión, por otro lado, está presente no solo en la sociedad sino también en la Iglesia. Por ello, Francisco insiste en la ternura que hará posible una Iglesia cercana y servidora en todas las dimensiones de la sociedad:

La ternura [...] necesita del pensamiento de la alteridad, con la que debe confrontarse continuamente para evitar el peligro - siempre posible - de reducirse a una compensación intimista o a una condescendencia con los vacíos del corazón humano, [...] Solo gracias a la ternura el pensamiento de la alteridad entra en el corazón de los individuos y de la sociedad y transforma la cultura de la identidad o del individualismo en una cultura de la solidaridad y del amor. En este nivel se coloca el valor "político" de la ternura. (Rocchetta, 2001, p 73)

La ternura, para Francisco (2014), es, pues, fruto del esfuerzo humano y de la gracia divina que hace de los creyentes instrumentos de Dios: "Hagámonos 
instrumentos de esta misericordia, cauces a través de los cuales Dios pueda regar la tierra, custodiar toda la creación y hacer florecer la justicia y la paz". Si Arquímedes afirmaba "dame un punto de apoyo y moveré el mundo", Francisco manifestaría: dame misericordia y transformaré el mundo, puesto que "la ternura es la fuerza más humilde; pero es la que tiene mayor poder para cambiar el mundo" (Rocchetta, 2001, p. 13). La espiritualidad de la ternura a la que lanza Francisco tiene que ver con una gran dosis de humildad en el sentido expresado por Dostoievski: "La humildad amorosa es una fuerza terrible, la más fuerte de todas, no hay nada que se le parezca" (2000, p. 463). Solo así se entiende que

la adquisición de la ternura, [...] supone el coraje de comprometerse con alguien, el coraje de abrirse al prójimo con gestos concretos, más allá de las respuestas negativas que se pueden recibir, el coraje de arriesgarse uno mismo por amor, con afecto sincero y discreto. [...] Ser tiernos con fortaleza y fuertes con ternura, este es uno de los grados más elevados de perfección moral. (Rocchetta, 2001, p. 46)

Bien se puede concluir que Francisco nos quiere proponer vivir la ternura como mística, que supone el modo de ver al ser humano, al mundo, a la Iglesia y a la espiritualidad que se ha descrito antes.

\section{Una propuesta integradora y plenificadora: la mística de la ternura}

Se sabe que la palabra mística tiene raíces griegas (Pabón, 1991) (mystikós: misterio, derivado de mystes: iniciado). Dice de prácticas religiosas cerradas, reservadas para iniciados. Hace relación con el hecho de cerrar los ojos (myein) y mirar al interior. El cristianismo tomó del griego esta palabra para expresar su experiencia de Dios, pero alteró radicalmente el concepto. En el Nuovo dizionari di spiritualita, se lee sobre mística: con este término pretendemos referirnos a ese momento o nivel o expresión de la experiencia religiosa en la que un mundo religioso determinado se experimenta como una experiencia de interioridad e inmediatez. También se podría, y quizá mejor, hablar de una experiencia religiosa particular de unidadcomunión-presencia, donde lo que se "conoce" es precisamente la realidad, lo que se da de esta unidad-comunión-presencia; no una reflexión, una conceptualización, una representación de los datos religiosos vividos (Moioli, 1983, p. 985).

Por tanto, la mística cristiana es una experiencia de "unidad-comunión presencia". Experiencia posibilitada por la fe en el Dios de la Alianza. Es Dios quien 
obra dicha unidad, comunión con el creyente, quien reconoce y acoge tal presencia como pecador, humildemente y desde su fragilidad humana. Esta experiencia plenificada en el encuentro vivo con Jesucristo y en su progresiva identificación con Él se hace comunión-unidad con Cristo. En este sentido, la mística es un encuentro tierno con Cristo. Por eso, la experiencia mística cristiana se hermana con la perfección cristiana en la caridad. No es posible ser místico y no vivir la caridad. Por ello, la figura nupcial de la mística explica muy bien su verdadero sentido: el símbolo nupcial se entiende como capaz de expresar la experiencia no necesariamente de ser uno, sino del ser unido de comunión en transformación, de la presencia que llama la atención, del amor recibido que hace el amor en uno; una nueva forma inédita (Moioli, 1983, pp. 989-990).

Se trata de un nuevo modo de amar en Dios, al mundo y a los demás. Es mística la experiencia gratuita iniciada por Dios en un gesto de su mayor ternura en el creyente, que hace posible en el sujeto, que acoge con ternura, una experiencia cumbre, de plenitud humano-espiritual de unidad-comunión presencia. En palabras de Francisco (2017), sería “el diálogo entre el poder de Dios y el barro". Como toda experiencia es incomunicable pero no imparticipable, no es privilegio de unos pocos, ni es algo espectacular, sino de cualquier creyente que se ha dejado permear en su vida total por la acción del Espíritu Santo y ha dejado crecer la gracia recibida en el bautismo hasta que Cristo viva en él (Ga 2, 20). Tampoco es una experiencia que aparta del mundo, sino que es a partir de ella que se tiene una especial "novedad" para mirar, relacionarse y transformar el mundo y la sociedad con los mismos sentimientos de Jesús hasta que se realice el Reino.

Hoy más que nunca la humanidad necesita una mística de la ternura en vez de intentos individuales e intimistas. Es urgente redefinir los fines y objetivos de la convivencia humana y los caminos para lograrlos, ya que se está en un mundo globalizado que transforma la interdependencia en dominio de unos pocos sobre el conjunto. Solo con la mística comunitaria basada en la ternura será posible converger, cooperar y dialogar con autenticidad. Se trata de una

adhesión al Reino, a la nueva manera de ser, de vivir juntos, que inaugura el Evangelio. Tal adhesión, que no puede quedarse en algo abstracto y desencarnado, se revela concretamente por medio de una entrada visible, en una comunidad de fieles. Así pues, aquellos cuya vida se ha transformado entran en una comunidad que es en sí misma signo de la transformación, signo de la novedad de vida. (Pablo VI, 1975, n. 23)

Urge superar los errores de la posmodernidad: el individualismo y el "capitalismo salvaje". Hoy los medios no "comunican", el uso de internet por sí mismo 
no une al mundo. Solo informan o masifican y agigantan las desigualdades, la brecha entre ricos y pobres se hace más inconciliable. Hay que creer que la Iglesia ofrece una respuesta: rehacer el tejido social roto por el individualismo y la insolidaridad. Esto solo es posible desde una espiritualidad basada en nuevas relaciones de diálogo, de ternura. Relaciones llamadas a crecer por amor, hasta llegar a una verdadera comunión.

La mística de la ternura se basa en la comunión con Cristo, se demuestra y celebra en la comunión fraterna y ecológica. Vivir la mística de la fraternidad/ sororidad será posible desde una Iglesia de la misericordia, cuya principal “obsesión" será abolir las diferencias que el pecado del mundo consagra siempre en las relaciones humanas. En la Iglesia misericordiosa, "no habrá varón ni mujer" (Ga $3,28)$, ni rico ni pobre, ni blanco ni negro, ni occidental u oriental, sino solo personas nuevas. En palabras de Francisco: “¡Cómo me gustaría una Iglesia pobre y para los pobres! (Hernández, 2013). Y esa Iglesia buscará hacer todo lo posible para no dar ocasión de pensar que ella mantiene esas diferencias abolidas por Cristo.

Desde América Latina, la mística de la ternura tiene una incidencia especial en la transformación de las relaciones sociales de modo que sean igualitarias e inclusivas. No podrá ser mística de ternura si los pobres no se sienten parte de la comunidad eclesial, si no intervienen en toda la dinámica eclesial y si no van dejando de ser pobres, gracias a que se han encontrado con ellos caminos solidarios de justicia social. Ya Medellín denunciaba: “La pobreza de tantos hermanos clama justicia, solidaridad, testimonio, compromiso, esfuerzo y superación para el cumplimiento pleno de la misión salvífica encomendada por Cristo" (Consejo Episcopal Latinoamericano [Celam], 2014, n. 7). "En esta perspectiva, para un cristiano, el compromiso con los pobres no está motivado, en primer lugar, por razones de orden social - por importantes que ellas sean - sino por la fe en un Dios amor ante quien debemos reconocernos como hijas e hijos y por lo tanto como hermanos entre nosotros" (Gutiérrez, 2006, p. 32). Esta dinámica de intercambio de bienes diversos como parte de una auténtica comunión ha sido reforzada por todas las conferencias episcopales latinoamericanas.

En Puebla, se hace un llamado a la conversión hacia una verdadera justicia social (Celam, 2014, n. 30), invitando a un "amor que abraza a todos los hombres. Amor que privilegia a los pequeños, los débiles, los pobres. Amor que congrega e integra a todos en una fraternidad capaz de abrir la ruta de una nueva historia" (n. 192). El documento también pone un criterio de la autenticidad de la evangelización: "el amor preferencial y la solicitud por los pobres y necesitados" (n. 382); pide que se revise la unidad eclesial con la comunión y participación 
con los pobres y sencillos (n. 974), así como incita a que se revise la medida del seguimiento a Cristo con el servicio a los pobres (n. 1145), y más aún señala que, gracias al potencial evangelizador de los pobres en las comunidades eclesiales de base (CEB), la Iglesia toda se siente interpelada a una vida de valores de comunión (n. 1147). Por esta razón, Puebla imprime rasgos de una mística de la ternura centrada en la opción preferencial por los pobres en medio de una sociedad plural como testimonio de anuncio de la Iglesia.

Santo Domingo, por su parte, ve en el ejemplo de Cristo una interpelación para "dar un testimonio auténtico de pobreza evangélica en nuestro estilo de vida y en nuestras estructuras eclesiales, tal cual como Él lo dio" (Celam, 2014, n. 178), en pro de "promover un nuevo orden económico, social y político, conforme a la dignidad de todas y cada una de las personas, impulsando la justicia y la solidaridad y abriendo para todas ellas horizontes de eternidad" (n. 296). Aparecida relee la realidad actual latinoamericana donde "conviven diferentes categorías sociales tales como las élites económicas, sociales y políticas; la clase media con sus diferentes niveles y la gran multitud de los pobres" (n. 512) y donde "ya no se trata simplemente del fenómeno de la explotación y opresión, sino de algo nuevo: la exclusión social" (nn. 65, 89, 42, 503). Allí se reconocen desde la fe tales escenarios como una sombra eclesial (n. 514) y se responsabiliza a la Iglesia de tal situación: "Si muchas de las estructuras actuales generan pobreza, en parte se ha debido a la falta de fidelidad a sus compromisos evangélicos de muchos cristianos con especiales responsabilidades políticas, económicas y culturales" (n. 501). Asimismo, se alegra de que el pueblo latinoamericano, no obstante sus limitaciones eclesiales, goce "de un alto índice de confianza y de credibilidad por parte del pueblo. Es morada de pueblos hermanos y casa de los pobres" (n. 8). Pueblo sufriente y afligido que da testimonio de evangelización (n. 257). Para Aparecida, los pobres, pues, "interpelan el núcleo del obrar de la Iglesia, de la pastoral y de nuestras actitudes cristianas" (n. 393).

La mística de la ternura, por tanto, es una experiencia que hace posible y visible la llegada de Reino en el mundo, cuyo fruto será un testimonio de continua conversión que irá creando nuevas y cada vez más profundas relaciones con Dios, con los demás y con la naturaleza. Comunión, por ello, vital, donde se une lo divino, lo humano y lo cósmico en un canto de alabanza a Dios a través de las obras diarias y en el mundo. Así, la mística de la ternura es la experiencia de vida plena en el Espíritu. Vida posibilitada por el encuentro personal con Dios, encuentro interpelante con los demás seres creados y encuentro creativo. Vida que no tiene más remedio que ser alegre. 


\section{Conclusión}

El pontificado de Francisco está irrumpiendo en la Iglesia y el mundo con la intención clara de salir de un cristianismo mediocre, que yendo a lo esencial, se cambie por uno verdadero. Mirar a Cristo y la vida de los primeros cristianos para ser "signos de contradicción" en este mundo antihumano (insolidario, excluyente y perverso), y mostrar que todavía se puede ser minoría profética desde la convicción de que se cree en un Dios kenótico, pobre y misericordioso. Si en la Biblia la misericordia tiene siempre la última palabra (sobre la venganza y la justicia), sus discípulos no pueden querer lo contrario.

La "revolución de la ternura", por tanto, es una invitación a la radicalidad de vivir el evangelio de la ternura, a ser sacramento de la ternura, siendo místicos de la ternura, llegar a ser, finalmente, mártires de la ternura. Revolución que en nuestros tiempos es urgente frente a la dureza y cerrazón de la comunidad cristiana ante los seres humanos y ante el cosmos. Esto supone arriesgarse, gastarse, entregarse para primerear y fecundar en el mundo a través de gestos concretos, de vulnerabilidad y convicciones, humildad y valentía, "para que todos podamos redescubrir la alegría de la ternura de Dios" (Francisco, 2015).

\section{Referencias}

Alvarado, A. (2015). La mística del diálogo como camino espiritual para una santidad en y para el mundo: hacia una espiritualidad laical para América Latina (Tesis de grado). Universidad Pontificia Bolivariana, Medellín, Colombia.

Andrade, B. (1999). Dios en medio de nosotros: esbozo de una teología trinitaria kerigmática. Salamanca, España: Secretariado Trinitario.

Biblia de Jerusalén (1998). Bilbao: Desclée de Brouwer.

Boff, L. (16 de febrero de 2014). Ternura: la savia del amor. Leonardo Boff. Recuperado de https://leonardoboff.wordpress.com/2014/02/16/ternura-la-savia-del-amor/

Bonhoeffer, D. (2004). El precio de la gracia: el seguimiento (5.a ed.). Salamanca, España: Sígueme.

Cappellaro, B. (2008). Spiritualità di comunione: un'esperienza, una teologia, una pastorale. Bolonia, Italia: Edizioni Dehoniane.

Castillo Sánchez, J. M. (2002). La Iglesia que quiso el Concilio. Madrid, España: PPC.

Concilio Vaticano II (1995). Documentos completos. Bogotá, Colombia: San Pablo. 
Consejo Episcopal Latinoamericano (2014). Las cinco conferencias generales del episcopado latinoamericano. Río de Janeiro, Medellín, Puebla, Santo Domingo, Aparecida. Bogotá, Colombia: Autor.

Domínguez, C. (2003). Místicos y profetas. Selecciones de Teología, 165, 3-15.

Dostoievski, F. (2000). Los hermanos Karamázov. Madrid, España: Debate.

Eymar, C. (2007). La espiritualidad de los laicos a la luz del vaticano II. Revista de Espiritualidad, 66, 247-294.

Francisco (2013). Encuentro con los representantes de los medios de comunicación. Discurso del Santo Padre Francisco. Recuperado de http://w2.vatican.va/content/francesco/ es/speeches/2013/march/documents/papa-francesco_20130316_rappresentantimedia.html

Francisco (2014). Exhortación apostólica Evangelii gaudium. Bogotá, Colombia: San Pablo.

Francisco (2014). Audiencia General. Plaza de San Pedro. Recuperado de http:// w2.vatican.va/content/francesco/es/audiences/2014/documents/papa-francesco_20140910_udienza-generale.html

Francisco (2015). Carta encíclica Laudato si'. Bogotá, Colombia: San Pablo.

Francisco (2015). Misericordiae vultus. Bula de convocación del jubileo extraordinario de la misericordia. Recuperado de http://w2.vatican.va/content/francesco/es/bulls/documents/papa-francesco_bolla_20150411_misericordiae-vultus.html

Francisco (2016). Audiencia General. Recuperado de http://w2.vatican.va/content/francesco/es/audiences/2016/documents/papa-francesco_20160615_udienza-generale.html

Francisco (2017). Misas matutinas en la capilla de la Domus Sanctae Marthae. Reconocer nuestra vulnerabilidad. Recuperado de http://w2.vatican.va/content/francesco/es/ cotidie/2017/documents/papa-francesco-cotidie_20170616_vulnerabilidad.html

González Buelta, B. (2006). Ver o perecer: mística de los ojos abiertos. Santander, España: Sal Terrae.

Gutiérrez, G. (2006). La koinonía eclesial. Páginas, 31(200), 18-35.

Juan Pablo II (1989). Christifideles laici (2. ㄹ Ed.). Bogotá, Colombia: Paulinas.

Haas, A. (2003). La mística de la encarnación. Communio: Revista Católica Internacional, $25,35-46$.

Hernández Velasco, I. (16 de marzo de 2013). El Papa: “¡Cómo me gustaría tener una Iglesia pobre y para los pobres!". El Mundo. Recuperado de https://www.elmundo.es/elmundo/2013/03/16/internacional/1363428945.html

Martínez, M. (2006). La perfección cristiana en el pensamiento de Antonio Royo Marín. Ciencia Tomista, 133(3), 417-446. 
Moioli, G. (1983). Mística cristiana. En S. de Fiores, T. Goffi y E. Paoline (eds.), Nuovo dizionari di spiritualita (pp. 985-1001). Roma, Italia: Edizione Paoline.

Pabón de Urbina, J. (1991). Diccionario manual griego clásico-español (17.․ed.). Barcelona, España: Vox.

Pablo VI (1975). Evangelii nuntiandi. En Encíclicas de Pablo VI (pp. 323-426). Madrid, España: Edibesa.

Pablo (1964). Lumen gentium. Recuperado de http://www.vatican.va/archive/hist councils/ii_vatican_council/documents/vat-ii_const_19641121_lumen-gentium _ sp.html

Pablo (1965). Gaudium et spes. Recuperado de http://www.vatican.va/archive/hist_ councils/ii_vatican_council/documents/vat-ii_const_19651207_gaudium-etspes_sp.html

Panikkar, R. (2007). De la mística: experiencia plena de vida. Barcelona, España: Herder.

Pikaza, X. (2006). Antropología bíblica: tiempos de gracia. Salamanca, España: Sígueme.

Rocchetta, C. (2001). Teología de la ternura: un evangelio por descubrir. Salamanca, España: Secretariado Trinitario.

Torralba Rosello, F. (2014). La revolución de la ternura: el verdadero rostro del papa Francisco. Lleida, España: Milenio.

Velasco, J. M. (2007). Mística y humanismo. Madrid, España: PCC. 